\title{
Estimated number of leprosy cases in the world*
}

\author{
S K NOORDEEN ${ }^{\mathrm{a}}$, L LOPEZ BRAVO ${ }^{\mathrm{b}}$ \& \\ T K SUNDARESAN"
}

${ }^{a}$ Chief Medical Officer, Leprosy Unit, World Health Organization, 1211 Geneva 27, Switzerland

${ }^{\mathrm{b}}$ Medical Officer, Leprosy Unit, World Health Organization ${ }^{\mathrm{c}}$ and Consultant

Planning for leprosy control requires estimates of the number of leprosy patients at different levels. During the period between the mid-1960s and the mid-1980s, global estimates had remained constant at between 10 and 12 million. The introduction of multidrug therapy (MDT) in many countries and the consequent reduction of the disease's prevalence has necessitated a reassessment of this. Based on available information and its interpretation, the number of leprosy cases in the world for 1991 has been estimated at 5.5 million. The number of individuals deformed by leprosy, including those cured of the disease, has been estimated at between 2 and 3 million.

\section{Introduction}

Leprosy continues to be an important public health problem in most parts of Asia, Africa and Latin America. The magnitude of the problem is often expressed by the number of cases registered by the leprosy programmes, although it is recognized that registered cases do not reflect all the cases existing in any given area. Therefore, from time to time, attempts have been made to estimate the prevalent number of cases at national, regional and global levels. More recently, and particularly since 1985, the leprosy situation in many parts of the world has undergone major changes, following the widespread introduction of multidrug therapy (MDT) as recommended by the WHO Study Group on Chemotherapy of Leprosy for Control Programmes in 1981. ${ }^{1}$ This has necessitated updating the current global estimate of leprosy cases so that future strategies and planning are based on more updated information.

\section{Problems in estimating leprosy}

Estimates on disease prevalence are generally based on well-planned, sample surveys. In fact this had been attempted in limited situations ${ }^{2}$ for estimating leprosy prevalence and

* This paper is reproduced from the WHO Bulletin $(1992,70$ (1) 7-10) by kind permission of WHO. 
detailed methods have also been outlined. ${ }^{3}$ However, in terms of obtaining prevalence information for large areas or countries as a whole, sample surveys are neither practicable nor cost-effective. The main reasons for this are the very low frequency of occurrence of leprosy and its uneven distribution which demand huge sample sizes in order to attain reasonable levels of precision. Even more, non-sampling errors, including inadequate coverage for examination of individuals, observer variations, and varying and imprecise case definitions, introduce gross inaccuracies which make even total population surveys difficult to interpret. In spite of the above problems, estimates on leprosy prevalence are required at different levels and therefore attempts have been made to make estimates by applying indirect methods, involving extrapolations through application of correction factors to already available information, for instance on the number of registered cases. Such correction factors have been derived from apparently reliable information available from limited areas. Extrapolations have also been attempted from information on prevalence among children, ${ }^{4}$ prevalence of deformities, and even from rapid village surveys. Sometimes a combination of more than one method has been suggested. ${ }^{5}$ It should be recognized that, although from the purely statistical point of view the precision of many of the estimates can be questioned, the estimates in general have been found to be reasonably adequate for planning purposes.

\section{Previous estimates on the global problem of leprosy}

The magnitude of the global problem of leprosy has been expressed by the WHO, through estimates on the number of prevalent cases in the world at any one time. Such estimates have been found to be valuable for planning and priority setting. In 1966, based on a country by country analysis, it was estimated that the total number of cases in the world was $10,786,000^{6}$. The figure was updated in $1972^{7}$ giving estimates of 10,407,200 cases. The WHO Expert Committee in its fif th report estimated a figure of over 12 million cases. ${ }^{8}$ The WHO Study Group on Epidemiology of Leprosy in Relation to Control in $1983^{9}$ referred to an estimate of $11,525,000$ cases. Since then, an estimated figure of 10-12 million has been frequently mentioned in several documents. All the above attempts at making estimates have assumed that the leprosy situation, in different countries and globally, has been rather static in terms of numbers, that elimination of the disease through cure and death has been compensated for in full by the occurrence of new disease, and that case definitions had remained unchanged.

\section{Methods applied for making current estimates}

It is well known that leprosy is very unevenly distributed at the global, national and even at the sub-national levels. Information on registered cases clearly indicates that the top 25 countries contribute nearly $95 \%$ of all registered cases in the world, of which the top 5 contribute $82 \% .{ }^{10}$ Therefore, in order to make a reasonably reliable global estimate of the prevalence of the disease, greater attention was given to making estimates for the top 25 
countries, and estimates were made on a detailed review of information on registered cases. In the case of the top 5 countries, estimates were arrived at following more intensive reviews of all the available information and discussion with relevant programme managers. In general, estimates for the 25 countries were arrived at by applying correction factors to registered cases, in addition to extrapolating from other related information as well as reviewing information provided by WHO consultants and programme managers. For leprosy-reporting countries/territories other than the top 25, numbering some 127 , estimates were made by developing and applying appropriate correction factors for each WHO Region, unless more reliable information was available for any country, including some that had been collected earlier through a questionnaire. The correction factor for each Region was calculated as the ratio between the registered cases in those countries of the Region included in the top 25 and estimates made earlier for them. Although admittedly this is a crude method, it was found to be reasonably satisfactory for making global estimates.

\section{Estimated number of cases in the world}

Based on the methodology indicated earlier, the global number of leprosy cases, as of 1991, has been estimated at about 5.5 million. This figure is about half the 10-12 million estimated during the 1960s, 1970s and 1980s. This large reduction is a result of (a) the large number of patients cured through MDT which has a finite period of treatment; (b) eliminating from existing registers those individuals who do not qualify as 'cases', as defined by the WHO Expert Committee on Leprosy in its sixth report, ${ }^{11}$ which recommended that for the purpose of prevalence only a patient requiring or receiving chemotherapy should be recognized as 'a case of leprosy'; (c) possible late effects of intensive dapsone-based control activities in some areas; (d) strengthening leprosy control activities in many countries whilst introducing MDT; and (e) natural declining trends as observed in some parts of Africa. Table 1 provides information on the estimated cases according to WHO Regions and by countries grouped according to number of cases.

Table 1. Number $(\times 1000)$ estimated cases in countries by WHO Region (1991) (figures in parenthesis refer to number of countries involved)

\begin{tabular}{lrrrrrrr}
\hline & \multicolumn{7}{c}{ WHO Regions $^{\mathrm{a}}$} \\
\cline { 2 - 7 } $\begin{array}{l}\text { Estimated Cases } \\
\text { in Countries }\end{array}$ & AFR & AMR & EMR & EUR & SEAR & WPR & TOTAL \\
\cline { 2 - 7 } 200 or more & $360(1)$ & $270(1)$ & $0(0)$ & $0(0)$ & $3440(3)$ & $0(0)$ & $4070(5)$ \\
$100-199$ & $0(0)$ & $0(0)$ & $0(0)$ & $0(0)$ & $250(2)$ & $120(1)$ & $370(3)$ \\
$20-99$ & $375(9)$ & $57(2)$ & $152(3)$ & $0(0)$ & $54(1)$ & $87(2)$ & $725(17)$ \\
$1-19$ & $178(21)$ & $60(10)$ & $52(8)$ & $7(2)$ & $5(2)$ & $28(7)$ & $330(50)$ \\
less than 1 & $3(15)$ & $4(27)$ & $3(10)$ & $2(12)$ & $1(1)$ & $3(12)$ & $16(77)$ \\
Total & & & & & & & \\
& $916(46)$ & $391(40)$ & $207(21)$ & $9(14)$ & $3750(9)$ & $238(22)$ & $5511(152)$ \\
\hline
\end{tabular}

${ }^{\text {a }} \mathrm{AFR}=\mathrm{Africa} ; \mathrm{AMR}=$ Americas; $\mathrm{EMR}=$ Eastern Mediterranean; EUR = Europe; $\mathrm{SEAR}=$ South-East Asia; and WPR $=$ Western Pacific 


\section{Estimated number of leprosy patients and former patients having deformities}

While the estimate of 5.5 million relates to cases requiring or receiving chemotherapy, there are a large number of patients who have been cured and discharged from registers but still have residual deformities of WHO grade $2^{12}$ resulting from past leprosy. These individuals constitute a substantial burden to the community from the rehabilitation point of view. Currently, as most leprosy programmes are not involved in rehabilitation activities they do not possess or maintain information on such patients, although there is some information available on patients under treatment who have deformities. With the increasing application of MDT and the large number of patients being discharged from registers, some programmes are increasing their focus on deformed patients, whether under treatment or cured. It, therefore, becomes important to make estimates for such individuals. It is possible to attempt to estimate the number of deformed patients by making reasonable assumptions on (a) the estimated number of new cases in the past, going back at least 50 years; (b) the proportion of such cases ultimately developing deformities; (c) the survival rate of deformed patients; and (d) the intensity and efficacy of leprosy control activities. In order to make an estimate for the number of persons in the world deformed by leprosy and surviving through 1991, assumptions were made on the above factors and different figures covering different periods were assumed for the estimated new cases, the proportion who became deformed, and the survival rates. Depending upon the assumptions made, the estimates arrived at varied between 2 and 3 million deformed individuals, irrespective of whether or not they had active disease. Thus, it is reasonable to conclude that by 1991 there were an estimated 2-3 million individuals in the world who had deformities (WHO Grade 2) caused by leprosy.

\section{Estimated number of cases in the top 25 countries}

Table 2 gives information on the estimated number of cases for the top 25 countries and also the number of registered cases in each country by WHO Region. They also happen to be countries with more than 20,000 cases each.

The 25 countries having the largest number of estimated leprosy cases and contributing $93.7 \%$ of the total estimated cases in the world are discussed here purely from the point of view of their contribution to the total global case-load. They are not necessarily the top 25 countries from the point of view of estimated rate of prevalence. Thus, their ranking for the estimated number of cases and the estimated prevalence rate would vary considerably. However the top 25 , from the point of view of total estimated cases generally, coincides with the top 25 from the point of view of total registered cases (except for 3 countries) although the individual rankings within the 25 vary.

\section{Discussion and conclusions}

It is clear that, for planning purposes, there is a need to have estimates of leprosy patients at different levels irrespective of the limitations and imperfections with regard to available information or methodologies. At the global level, there is an urgent need to update the figures particularly in view of the major changes that have taken place over the past 7-8 
Table 2 Number $(\times 1000)$ of estimated and registered cases in the top 25 countries by WHO Region (1991)

\begin{tabular}{|c|c|c|}
\hline Region & Estimated & Registered \\
\hline \multicolumn{3}{|l|}{ Af rica } \\
\hline Nigeria & 360 & 156 \\
\hline Mozambique & 65 & 24 \\
\hline Ethopia & 60 & 16 \\
\hline Zaïre & 58 & 9 \\
\hline Madagascar & 50 & 19 \\
\hline Côte d'Ivoire & 40 & 14 \\
\hline Uganda & 30 & 8 \\
\hline Mali & 28 & 13 \\
\hline Cameroon & 22 & 10 \\
\hline Chad & 22 & 11 \\
\hline Sub total & 735 & 280 \\
\hline \multicolumn{3}{|l|}{ South-east Asia } \\
\hline India & 3000 & 1996 \\
\hline Myanmar & 240 & 112 \\
\hline Indonesia & 200 & 102 \\
\hline Bangladesh & 150 & 25 \\
\hline Nepal & 100 & 25 \\
\hline Thailand & 54 & 13 \\
\hline Sub total & 3744 & 2273 \\
\hline \multicolumn{3}{|l|}{ Americas } \\
\hline Brazil & 270 & 260 \\
\hline Colombia & 31 & 19 \\
\hline Argentina & 26 & 16 \\
\hline Sub total & 327 & 295 \\
\hline \multicolumn{3}{|l|}{ Eastern Mediterranean } \\
\hline Sudan & 52 & 36 \\
\hline Egypt & 50 & 7 \\
\hline Iran & 50 & 14 \\
\hline Sub total & 152 & 57 \\
\hline \multicolumn{3}{|l|}{ Western Pacific } \\
\hline Viet Nam & 120 & 20 \\
\hline Philippines & 47 & 39 \\
\hline China & 40 & 30 \\
\hline Sub total & 207 & 89 \\
\hline Total 25 countries & 5165 & 2994 \\
\hline Total all countries in the world & 5511 & 3162 \\
\hline
\end{tabular}

years as a result of the implementation of MDT and related activities. It is also important to recognize that a proportion of cured patients have residual deformities requiring rehabilitative support, and it is therefore necessary to estimate the deformity load in the community in addition to estimating the magnitude of the problem from the disease and chemotherapy perspective.

The current estimate of 5.5 million cases may be considered by some as an underestimate, particularly in relation to previous estimates. On the other hand, the 
current estimates, as derived from information on registered cases, may be considered as an overestimate by some, particularly in relation to the situation in some countries where the registered cases include a substantial proportion of inactive cases. In relation to possible underestimation, it should be recognized that the previous estimates of $10-12$ million were made several years ago and since then drastic changes have occurred in the leprosy situation. It should, therefore, be recognized that the reduced estimate reflects the outcome of successful leprosy control activities in recent years. It is also clear that the opportunity to further reduce prevalence through intensified control using MDT is very considerable, and the estimate may fall further in the future if the anticipated intensification of leprosy control materializes. In addition, there is a need to address the rehabilitative needs of the estimated 2-3 million deformed individuals by implementing existing technologies and developing better technologies and strategies and applying them widely.

\section{References}

1 WHO Technical Report Series, No. 675, 1982 (Chemotherapy of leprosy for control programmes: report of a WHO Study Group).

2 Bechelli L M, Martinez Dominguez V, Patwary K M. WHO epidemiological random sample surveys of leprosy in N. Nigeria, Cameroon and Thailand. Int J Lepr, 1966; 34: 223-243.

3 Sundaresan T K. Sample survey in leprosy - an introductory manual. Unpublished WHO document. WHO/ CDS/LEP 86.1 1987.

${ }^{4}$ Bechelli L M et al. Proposed method for estimating leprosy prevalence based on rates in children. Bull WHO, 1973; 48: 502-503.

5 Report of a meeting on methods for rapid assessment of the leprosy situation, Geneva, 15-16 April 1988. Unpublished WHO document (WHO/CDS/LEP/88.2)

${ }^{6}$ Bechelli L M, Martinez Dominguez V. The leprosy problem in the world. Bull WHO, 1966; 34: 811-826.

7 Bechelli L M, Martinez Dominguez. Further information on the leprosy problem in the world. Bull WHO, 1972; 46, 523-536.

$\checkmark$ WHO Technical Report Series, No. 607, 1977. (WHO Expert Committee on Leprosy: fifth report).

9 WHO Technical Report Series, No. 716, 1985 (E pidemiology of le prosy in relation to control: report of a WHO Study Group).

10 Noordeen S K, Lopez Bravo L, Daumerie D. Global review of multidrug therapy in leprosy. World Health Statistics Quarterly, 1991; 44: 2-18.

11 WHO Technical Report Series, No. 768, 1988 (WHO Expert Committee on leprosy: sixth report).

12 World Health Organization-A Guide to Leprosy Control (Second edition), 1988. 